\title{
POESÍA, POLÍTICA Y ACTIVISMO
}

Poetry, politics and activism

ARTURO BORRA

UNIVERSITAT DE VALÈNCIA (ESPAÑA) arturoborra@hotmail.com

RESUMEN: El ensayo parte del análisis de la novela "Leviatán" de Paul Auster para reconstruir un contrapunto entre dos formas de concebir una práctica literaria crítica, políticamente comprometida, ligada a diferentes presupuestos acerca del autor, el lenguaje y el lector. A partir del análisis de esas concepciones, se formulan algunos interrogantes que permiten elucidar críticamente las implicaciones de cada posición.

PALABRAS CLAVE: Literatura, lenguaje, política, poesía, crítica, activismo.

ABSTRACT: The essay starts with the analysis of the novel "Leviatán" by Paul Auster to reconstruct a counterpoint between two ways of conceiving a critical and politically committed literary practice, linked to different assumptions about the author, the language and the reader. From the analysis of these conceptions, some questions are formulated that allow to critically elucidate the implications of each position.

KEYWORDS: Literature, language, politics, poetry, criticism, activism.

Borra, Arturo.

"Poesía, política y activismo".

Kamchatka. Revista de análisis cultural 11 (Julio 2018): 381-394

DOI: 10.7203/KAM.11.11354 ISSN: 2340-1869

Monográfico Lecturas del desierto: nuevas propuestas poéticas en España 
En El Leviatán (1993), Paul Auster construye un contrapunto tácito entre los dos personajes centrales del relato: Benjamin Sachs y Peter Aaron. A pesar de que ambos escritores mantienen una relación de amistad íntima y están marcados por la añoranza de otra sociedad o, en términos de Aaron, por “(...) la esperanza de que algún día podremos vivir en un mundo mejor" (Auster, 1993: 238), sus caminos son contrapuestos. Mientras que el primero, en su urgencia política, pasa de la novela al ensayo, abandonando posteriormente la literatura para dedicarse a atentar contra lugares emblemáticos (aunque sin provocar daño humano alguno y sólo daños materiales menores), el segundo personaje insinúa lo literario como una instancia diferenciada y relativamente autónoma que podría contribuir, al menos en ciertos casos, a elaborar específicos medios de lucha.

A Sachs le interesaban más la política y la historia que las cuestiones espirituales, pero sus opiniones políticas estaban no obstante teñidas de algo que yo llamaría una cualidad religiosa, como si el compromiso político no fuese solo una manera de enfrentarse a los problemas de aquí y ahora, sino también un medio de salvación personal (Auster, 1993: $38)$.

Sin entrar en los pormenores biográficos de la novela ni en los perfiles psicológicos que la sustentan, lo mínimo que cabe señalar al respecto es que si bien el modelo político de Sachs es Henry Thoreau, el pasaje de la literatura a la colocación de artefactos explosivos sólo se precipita por el hallazgo de unos textos de orientación anarco-marxista y una tesis sobre Alexander Berkman, persuadiéndolo sobre la necesidad de dar un primer paso hacia la "acción legítima" (sic) en un contexto político hegemonizado por el neoliberalismo de Ronald Reagan y la desaparición de la izquierda (Auster, 1993:121). ${ }^{1}$

Aunque el argumento que asocia anarquismo y (alguna forma de) violencia política podría rebatirse por tópico y reductivo, también es cierto que esta forma de activismo es-en tono dubitativo- justificado por Aaron:

Sus bombas no habían herido a nadie, y si esas insignificantes explosiones obligaban a la gente a replantearse su postura ante la vida, entonces tal vez no fueran una mala idea después de todo (Auster, 1993:239-240).

Mientras Sachs pasa -bajo el heterónimo de "El fantasma de la Libertad"- a una suerte de guerrilla urbana (colocando bombas en las diferentes réplicas de la Estatua de la Libertad diseminadas en EEUU), Aaron por su parte se dedica a escribir novelas, artículos y poemas; en particular, una suerte de biografía de su reciente amigo fallecido ${ }^{2}$. Con independencia a las implicaciones políticas y filosóficas de ambas opciones, bien podría ser que poner bombas fuera

\footnotetext{
${ }^{1}$ Tras el accidente fatal de Sachs, ocasionado por una bomba que estaba fabricando, Aaron se refiere a su amigo de la siguiente forma: "A pesar de su dulzura, Sachs podía ser rígidamente dogmático en su manera de pensar, y había veces en que se desataba en salvajes ataques de ira, estallidos de cólera verdaderamente terroríficos" (Auster, 1993: 30).

${ }^{2}$ El oficio de Aaron es modesto: “(...) un hombre que escribe novelas para ganarse la vida. (...) Sin saberlo siquiera, entro en la vida de los desconocidos, y mientras tienen mi libro en sus manos, mis palabras son la única realidad que existe para ellos" (Auster, 1993: 16).
} 
un "instrumento eficaz" para "revelarle al público la naturaleza del poder institucional" (Auster, 1993: 247). Pero incluso si dicho instrumento fuera la mejor estrategia de cambio político (lo que no es evidente de por sî), la pregunta ética de su amigo Aaron resulta ineludible: "Una bonita profesión si puedes meterte en ella, pero ¿quién diablos te ha elegido como conciencia del mundo?” (Auster, 1993: 245). La respuesta queda en el aire. En el mejor de los casos, la (auto)atribución de una misión política superior para acometer este tipo de actos resulta polémica: el "mesianismo" de quien se atribuye el lugar de la "conciencia del mundo" resulta insoslayable.

El hilo está sugerido por Auster: puede que el presunto "pasaje a la acción” (inmediata) se justifique sólo y en tanto el actor se plantee a sí mismo como "conciencia del mundo". Sin embargo, ¿a título de qué o de quiénes alguien se atribuye para sí la misión de hacer consciente al mundo de las contradicciones del "americanismo imbécil" (sic)? Incluso si el personaje se convierte en un "héroe popular clandestino" (sic) que tiene que afrontar el éxito de su acción, la legitimidad del acto no es clara. El mesianismo de Sachs no está basado en un consenso social previo ni es resultante de una decisión colectiva, sino una misión que el personaje se asigna a sí mismo y que sólo puede justificar a sus ojos como un paso que interrumpa, por así decirlo, el juego del lenguaje.

En última instancia, la legitimación subjetiva del acto mesiánico residiría en la posibilidad de una acción directa que trascienda el lenguaje -y particularmente la literatura- y redima lo social. Sin embargo, aun cuando sus atentados son "exitosos" en cuanto adquieren una importante resonancia social, la posición de Sachs se auto-refuta: en su intento de mostrar las contradicciones entre el símbolo de la libertad y la política marcada por el reaganismo no puede prescindir de acompañar sus actos con declaraciones verbales de todo tipo. No obstante su voluntad de escapar de la "cárcel del lenguaje" -por parafrasear a Jameson en su referencia a Nietzsche (1980)- sus actos tienen una dimensión simbólica ineludible. No habría eficacia alguna sin este "orden simbólico" sobre el que se incide. 3 De ahí que a pesar de su interpretación, Sachs no pasa del lenguaje a la acción sino de una acción lingüística a otra, aunque sus efectos materiales sean sin duda diferentes. Más aún, nuestro héroe clandestino necesita pasar por un difícil aprendizaje que implica "grandes cantidades de información técnica" para fabricar bombas, información bastante incomprensible por lo demás, que lo enfrenta a "un idioma extranjero que no lograba penetrar" (Auster, 1993: 256-257).

En síntesis, lo que desde la perspectiva de Sachs supondría un corte con lo lingüístico, en verdad, no es más que un cambio de lenguaje, vale decir, el pasaje de la literatura a una acción política que, no obstante sus intenciones declaradas, está atravesada por lo simbólico. El "Fantasma de la Libertad" -y la propia terminología ya es sintomática de este asedio fantasmático en el que nos movemos- obra en el campo de la discursividad. De ahí que poner pequeños

\footnotetext{
3 Siguiendo a Lacan, Zîzêk (en VVAA, 2004: 257) señala: "Esta dimensión del "gran Otro" es la de la alienación constitutiva del sujeto en el orden simbólico: el gran Otro tira de los hilos; el sujeto no habla, la estructura simbólica 'le habla'. En suma, este 'gran Otro' es el nombre de la Sustancia social, de todo aquello debido a lo cual el resultado final de su actividad siempre es algo distinto de aquello a lo que aspiraba o que anticipaba". Desde esta concepción, la posibilidad de autoengaño (en este caso, de Sachs) se hace patente: su aspiración a "salir de la jaula" es "algo distinto" a su actividad.
} 
artefactos explosivos es la acción de “(...) un artista que sabe que acaba de crear su obra más importante" (Auster, 1993: 254).

La posición enunciativa de Aaron es, por así decirlo, bastante más limitada:

Mi plan era revisar el manuscrito tantas veces como fuese necesario, añadir nuevo material en cada borrador sucesivo y seguir trabajando en ello hasta que pensase que no quedaba nada por decir (Auster, 1993: 267).

En efecto, el oficio de este escritor consiste en dejar un testimonio vital, dar cuenta del espesor de la existencia, necesaria, inexorablemente enlazada no sólo a otros específicos sino al lenguaje como condición de todo testimonio y, más en general, de toda comunicación intersubjetiva, inclusive si asumimos que las prácticas comunicacionales cotidianas rebasan regularmente el soporte verbal.

El trabajo de la literatura, así concebido, no conduce a una posición mesiánica sino a una crítica radical al material del lenguaje heredado. En otras palabras, desde esta perspectiva, se trata de reconocer la práctica de revisión de los manuscritos - en tanto borrador de la memoria- como colindante al acto de escribir. Semejante práctica obliga a trabajar hasta pensar que no queda "nada por decir". Lo que es afirmar: una tarea estrictamente interminable, incluso si se le pone un término temporal.

\section{-II-}

Un contrapunto análogo de posiciones podría repetirse dentro del campo de la "poesía crítica" de las últimas décadas en España (entendida como continente heterogéneo y no como un bloque estilística e ideológicamente uniforme), escrita en castellano: 1) aquella posición que, en su afán de priorizar la acción, arremete contra la retoricidad de lo poético, creyendo dinamitar el lenguaje en nombre de las urgencias de la lucha política cuando más bien tiende a normalizarlo en su uso inercial; y 2) aquella posición que mantiene una especificidad irreductible de lo poético con respecto a lo político, esto es, la suposición de que entre poesía y política hay una serie de mediaciones ineludibles, comenzando por la construcción de ese tipo de artefacto lingüístico que llamamos "poema". Si bien 1) no impugna el lenguaje a secas (lo que sería una contradicción manifiesta), exige salir de él; por su parte, 2) no niega la dimensión política de la poesía pero plantea una especificidad de la acción poética, consistente en construir obras de lenguaje que implican una elaboración formal significativa.

Mientras la primera posición poética llama a la acción política in-mediata (no mediada), la segunda asume que toda práctica poética produce, a lo sumo, efectos de sentido con un cierto potencial transformador, más o menos mediato. No sólo difieren en términos estilísticos o en sus respectivos lugares de enunciación; también difieren en el tipo de artefactos que conciben como apropiados para la producción de cambios sociales efectivos.

En este sentido, semejantes posiciones presuponen dos teorías del lenguaje contrapuestas entre sí, por más embrionarias que sean. Mientras la primera perspectiva plantea una clara separación entre "lenguaje" y "acción", la segunda perspectiva plantea una imbricación o una ligazón constitutiva entre ambas dimensiones. Toda práctica social -incluso aquella que es 
delimitada lingüísticamente como "acción directa"- implica una dimensión simbólica irreductible. Pretender salir de ahí no sólo es ilusorio: convierte el modesto oficio del escritor en un llamado mesiánico condenado estructuralmente al fracaso. De hecho, aun si semejante llamado tiene "éxito" en cuanto a lograr simpatías populares, tampoco Sachs logra por sí mismo su cometido (que no es otro que poner fin a la guerra).

La práctica poética, en suma, se constituye en diferentes actos de enunciación que -como toda otra forma de práctica- produce efectos específicos. El "decir", lejos de ser un "nivel" separado del "hacer", está íntimamente relacionado a éste: es una de sus formas específicas en determinados contextos institucionales. Por tanto, la performatividad de los "actos de habla" -y de la poesía como acto enunciativo-, antes que un rasgo contingente, es una condición central de la comunicación humana y forma parte de las premisas básicas de una filosofía contemporánea del lenguaje. 4 Para decirlo en terminología habermasiana (1987-1988): una "interacción simbólicamente mediada" que no produzca efectos recíprocos entre los participantes es una contradicción de los términos, esto es, una imposibilidad lógica.

Si la concepción del lenguaje de Sachs puede entenderse como "instrumentalista", la concepción de Aaron puede entenderse como "constructivista": el lenguaje no es un mero medio neutro que se podría usar con fines distintos sino una condición constitutiva de la sociabilidad y una toma de partido que, necesariamente, implica afrontar una serie de decisiones ideológicas. Si por una parte no hay nada semejante a un "sujeto humano" sin lenguaje, por otra parte, la elección de un vocabulario específico y su articulación discursiva en contextos institucionales y sociales determinados definen el lugar de enunciación concreto desde el que cada uno habla o escribe. La mera contraposición entre "lenguaje” y "acción” es, por tanto, incorrecta. Incluso si se establece una distinción analítica entre ambos, la interrelación entre uno y otro es fundante, lo que no significa que no se planteen contradicciones entre distintos momentos de las prácticas discursivas (que incluyen elementos lingüísticos y extralingüísticos) o entre diferentes planos significantes. ${ }^{5}$

Aunque a menudo dicho contrapunto se traduce en debates específicos con respecto a las estrategias de escritura poética apropiadas para dar lugar a la añoranza de otra sociedad (y de otra vida), lo decisivo es que no hay "escritura", "poesía" ni nada semejante a la "literatura" sin este soporte material del lenguaje. Obviar esa materialidad -y lo que implica poéticamente en términos rítmicos, sonoros y morfológicos- es, sencillamente, condenarse a la ceguera poética. Puesto que toda poética está enlazada a "juegos de lenguaje" específicos -por usar una categoría empleada por Wittgenstein-, pretender sustraerse de esos juegos en nombre de la acción política es sencillamente ilusorio. ${ }^{6}$ Salir de los "juegos de lenguaje" es el punto de imposibilidad ontológica

\footnotetext{
4 Además de las conocidas obras de Austin (1982), Searle (1994) y Wittgenstein (1988), cabe destacar los precursores estudios de Bajtin (1982) y Vosloshinov (1993). Para una reconstrucción crítica de las filosofías del lenguaje véase también Simon (1977) y Habermas (2011).

5 Para una teoría translingüística de lo discursivo, véase Verón, Eliseo (1988).

6 Wittgenstein utiliza la noción de "juego de lenguaje» para referirse “(...) al todo formado por el lenguaje y las acciones con las que está entretejido” (1988: 25). En este sentido, “(..) imaginar un juego de lenguaje significa imaginar una forma de vida" (1988: 31).
} 
por excelencia. La propia tesis sobre un más allá del lenguaje ya implica situarse en un juego de lenguaje específico para referirse a aquel.

La conclusión que se deriva de lo precedente es que una obra lingüística (o, de forma más acotada, un poema) que se atiene a una presunta inmediatez es una obra que, paradójicamente, desatiende o desconoce sus propios elementos constitutivos. Dicho de otra manera: se trata de una obra lingüística pre-crítica, independientemente a sus pretensiones formales o a sus adscripciones ideológicas explícitas. Así, la falta de atención crítica al lenguaje por parte de la posición instrumentalista pasa factura en el poema bajo la forma de un desinterés por el material con el que trabaja. El resultado es de sobra conocido: un cúmulo de poemas estéticamente irrelevantes y de dudoso valor político, por dejar intactas las categorías de pensamiento que sostienen y legitiman las condiciones del presente. ${ }^{7}$

-III-

Cualquiera fuera nuestro posicionamiento ante este contrapunto, lo que diferencia esas poéticas no es el "compromiso" con la izquierda ni el deseo de "cambiar el mundo", sino la forma de concebir ese compromiso y ese cambio. ${ }^{8}$ Benjamin Sachs no está más comprometido que Peter Aaron por poner bombas inofensivas: la eficacia de este tipo de actos también depende de los efectos disruptivos que provoca en el orden simbólico hegemónico.

Lo que está en juego, más bien, es el sentido del compromiso con el cambio. Pretender detentar el monopolio con ese compromiso es tan simplista como autoritario. Porque lo que se debate es, ante todo, cuáles son las modalidades apropiadas de las que ha de valerse la práctica poética para materializar el objetivo de apuntalar determinadas luchas en común.

A partir del texto de Auster, pues, cabe elaborar algunas preguntas en torno a ese compromiso concreto:

1) ¿Por qué habríamos de privilegiar lo poético como medio de lucha, cuando existen otras formas de participación política más efectivas, incluyendo nuestra inclusión como activistas en diferentes movimientos sociales, partidos políticos, asociaciones sindicales, organizaciones no gubernamentales, espacios educativos, plataformas ciudadanas comprometidas con la defensa de distintos derechos sociales, políticos, económicos y culturales y, más en general, con una política más o menos radical?

2) Si se admite que la poesía, en el mejor de los casos, constituye un medio de lucha entre otros, sin privilegio alguno desde el punto de vista de la efectividad política, ¿por qué habría de exigírsele una inmediatez que ninguna otra forma de práctica política está en

\footnotetext{
7 Riechmann (2007: 13) advierte a propósito de estos riesgos: “¿Poesía como vehículo de mensajes ideológicos? Es inadecuado - la poesía no debe reducirse a un papel instrumental, auxiliar; ella es señora, no sierva- y además es ineficaz -muy poca gente lee poesía; a menos todavía puede interesarles una tendenciosa poesía de "tendencia civil"-. Frente a todo esto, la poesía como práctica de indagación en todos los ámbitos: sin excluir lo social y lo político, por descontado".

8 Para una reflexión crítica en torno al concepto de "compromiso" en la poesía española del siglo XX remito a Méndez Rubio (2008) y Falcón (ed., 2007).
} 
condiciones de encarnar? En otras palabras, ¿por qué habría de demandarse a la poesía que cambie el mundo por sí sola cuando ninguno de los otros medios de lucha lo ha conseguido por sí mismo?

3) ¿Qué estrategias y tácticas poéticas resultan más apropiadas para tal fin? ¿Qué centralidad tienen los realismos, las vanguardias o las transvanguardias, entre otras perspectivas, como orientaciones divergentes de las prácticas poéticas?

4) ¿Qué presupuestos acerca del sujeto poético se ponen en juego en cada posición y qué lugar le asignan a la figura del poeta? ¿qué responsabilidad se atribuye al sujeto poético en cuanto a la transformación del mundo social?

5) Finalmente, ¿qué lugar le asigna cada posición a la figura del lector, en tanto destinatario de discursos que comparten el anhelo de una sociedad justa?

Sin ánimo conclusivo, me contentaré con plantear algunas respuestas provisorias y abiertas que apuntan al descentramiento -que no al desentendimiento- de la producción poético-literaria con respecto a la construcción de otra sociedad.

1) El discurso poético, como intervención política, carece de prerrogativas como medio de lucha. No sólo no excluye otras formas de activismo sino que, tanto por sus especificidades materiales y simbólicas como por el contexto sociocultural actual, dicha intervención tiene un radio de acción claramente reducido (habida cuenta del carácter minoritario de los públicos lectores de poesía). Si bien ciertos discursos poéticos constituyen habitualmente una forma específica y diferenciada de lucha, no hay razones para atribuirle un papel privilegiado en el campo político9. Desde una perspectiva histórica, no hay cambio social relevante que no presuponga un entrelazamiento de esas formas de lucha con otro tipo de prácticas políticas, a partir de una lógica articulatoria. Para retomar el argumento de Auster: bien podría ser que, en nuestro anhelo de cambiar el mundo, la literatura (o la poesía) sea radicalmente insuficiente. Si la respuesta de Sachs, ligada a una urgencia política, consiste en abandonar el espacio literario para dedicarse a construir artefactos explosivos, la respuesta de Aaron es si no contraria sí claramente diferenciada: seguir apostando, en el plano de la escritura, por una revisión crítica de su trabajo manuscrito. Como productor de artefactos lingüísticos, su compromiso consiste en elaborar simbólicamente un testimonio vital, no necesariamente de carácter autobiográfico, que permita dar cuenta de nuestras añoranzas y nuestras formas de vida. En suma, desde esta segunda posición, la literatura constituye una práctica exploratoria de la "realidad" a condición de no excluir de esa categoría (como suelen hacer los realismos estéticos) la indagación en la propia subjetividad, comenzando por nuestros sueños y anhelos. Como señala magistralmente Olga Orozco (1998: 83): "La realidad, sí, la realidad: /un sello de clausura sobre todas las puertas del deseo".

\footnotetext{
9 Como advierte Falcón (2010: 84), eludiendo la estratagema indigna de pretender erigirse en la "voz de los sin voz": "Si los poetas quieren dirigirse a los pobres, deberían bajar a la calle, trabajar en las organizaciones, conversar con ellos y ser dignos de poder ser invitados a entrar en sus casas. (...) En España hay más presos que lectores de poesía”.
} 
2) Aun si incluimos la poesía como un medio de lucha entre otros, el discurso poético puede en el mejor de los casos contribuir a producir determinados efectos de sentido que impliquen cambios más o menos (im)perceptibles en algunos destinatarios. No obstante, como cualquier otra práctica sociocultural, su aportación no sólo no es inmediata (puesto que supone procesos de recepción específicos que escapan al control del enunciador) sino que está claramente limitada y tanto más en un contexto de hegemonía audiovisual. Pretender que la poesía cambie el mundo -como si fuera un ámbito autosuficiente- es asignarle una misión mesiánica que, estructuralmente, no está en condiciones de cumplir. En cualquier caso, la efectividad de la poesía implica diversas mediaciones sociolingüísticas y no hay forma de salir de ahí como no sea recayendo en una ilusión de inmediatez, en nombre de la cual se impugnan otras posiciones poéticas ${ }^{10}$. No se trata, sin embargo, de una eficacia cuantificable -como no sea recayendo en las mediciones de audiencia, más próximas a las técnicas publicitarias que a los estudios de recepción-. Antes que interrogarnos sobre la eficacia o ineficacia de ciertas poéticas, entonces, se trata más bien de elucidar qué efectos de sentido se producen en diferentes lecturas (asumiendo la recepción como una instancia relativamente autónoma). Tanto la poesía más hermética como la poesía políticamente más explícita -asumiendo que existen modos y grados de elaboración simbólica diferenciados que, no obstante, pueden compartir finalidades políticas análogas- constituyen, en toda regla, construcciones lingüísticas determinadas, algunas de las cuales apelan a sugerentes condensaciones de sentido. De forma apriorística, ninguno de estos modos discursivos tiene más efectividad por la perspectiva estético-estilística que adopta, cualesquiera fueran nuestras preferencias. Así como Trilce de César Vallejo no tiene por qué tener menos eficacia política que Salmos de Ernesto Cardenal ni Las nadas y las noches de María Auxiliadora Álvarez tiene por qué ser menos efectivo que Ternura. Canciones de niños: rondas, canciones de la tierra, estaciones, religiosas y otras canciones de cuna de Gabriela Mistral, tampoco es claro que, por poner unos pocos ejemplos, Siguiendo los pasos del hombre que fue de David González, Disolución de Antonio Orihuela o Cartas de amor a un comunista de Isabel Montalbán sean más eficaces en términos políticos que La casa roja de Juan Carlos Mestre, La tierra prometida de Chantal Maillard o Elegía en Portbou de Antonio Crespo Massieu ${ }^{11}$ (sin que ello implique, por lo demás, introducir de contrabando juicios estéticos específicos en torno a los méritos y límites de cada obra en particular). A menos que planteemos un lazo causal necesario entre "comprensibilidad" y "efectividad", de lo uno no se deriva lo otro. Que un poema sea, en un momento dado, socialmente más asequible que otro, no lo torna más "efectivo" en términos políticos ni le confiere prerrogativas

\footnotetext{
10 No resulta extraño que junto a esta simplificación radical aparezca una ilusión concomitante: la ilusión de transparencia, esto es, la idea del lenguaje como espejo fidedigno del objeto. Con ello, no sólo se omiten las propias operaciones interpretativas del sujeto, sino las condiciones discursivas e institucionales de producción de toda "referencia". La crítica a la noción de "inmediatez", en la línea de la tradición hegeliana, ha sido efectuada de forma peculiarmente incisiva por Adorno (1983: 120 y ss. y 2008).

${ }^{11}$ Una reconstrucción tentativa de la actual poesía crítica en España ha sido realizada por García Teresa en Disidentes (2015). Si bien considero que dicha investigación no es exhaustiva, a pesar de la intención explícita del autor, constituye una contribución relevante para reconstruir cierta diversidad de propuestas estéticas críticas contemporáneas dentro del campo poético español.
} 
como producto comunicacional12. Que unos poemas concretos, en las condiciones de recepción actuales, resulten comparativamente más accesibles que otros no significa que, de cara a la acción política, tengan más fuerza interpeladora. Lo que para un tipo de público puede resultar ilegible, constituye para otro un aliciente para su reflexión o una conmoción de su sensibilidad; lo que para un lector u oyente podría resultar movilizador puede suscitar un bostezo en otro. Dicho de otra manera: más allá de cualquier consideración estética en cuanto a su calidad técnica e incluso con independencia a la validez teórica de las diferentes concepciones de la escritura poética, la eficacia de un texto (poético) -en tanto "potencial de efectos" al decir de Iser (1987)- depende en buena medida de su contexto de interpretación, especialmente de la actividad interpretativa del lector y no sólo ni prioritariamente de la intencionalidad comunicativa del autor. Lo que para una persona ajena al ámbito poético puede resultar altamente estimulante puede no serlo para quien se ha adentrado en este campo, pudiéndole resultar más bien banal, obvio o tópico. Teniendo en cuenta la pluralidad poética creada a lo largo de la historia humana, en definitiva, no hay ninguna razón válida para suponer que sólo ciertas formaciones poéticas (clasicistas, realistas, vanguardistas, posmodernistas) podrían incidir de forma efectiva en un proceso de transformación social. Puesto que no existe nada parecido a una solución formulaica, cada poética crítica traza específicas líneas de fuga. Dicho de otra forma: un mismo poema, en diferentes contextos históricos y culturales de recepción, puede ser juzgado de formas contrarias. Incluso si un poema es valorado en un contexto social dado de ahí no se infiere que esa aprobación conduzca a una práctica revolucionaria: entre el poema y la acción está el lector que, en última instancia, decide qué hacer con aquel. Hasta el más explícito llamamiento poético a la acción puede producir indiferencia o, sencillamente, ser desconocido en cuanto reclamo de un compromiso práctico. De hecho, considerando el carácter minoritario de los públicos que leen poesía en un contexto dominado por la cultura masiva, hay razones para suponer que ese llamamiento, cuando no es reiterativo (puesto que dichos públicos a menudo ya están persuadidos de la necesidad de propiciar un cambio social relevante), genera interpretaciones diferentes y hasta contrarias (introduciendo los propios matices de cada acto de lectura).

3) Por lo antedicho, al sujeto poético no le cabe ni más ni menos responsabilidad que a cualquier otro ciudadano $o$, si se prefiere, que a cualquier otro agente político. Ciertamente, en las actuales condiciones históricas, no cabe descartar como opción éticopolítica cambiar de oficio. Bien podría ser que ante la escalada de la derecha y la proliferación de injusticias históricas nos sintamos llamados, legítimamente, a desplazarnos a otras formas de acción. No hay ninguna incompatibilidad, sin embargo, entre escribir poemas y producir otras herramientas críticas o participar en otras modalidades de intervención política. Con todo, atribuirse como poeta alguna función privilegiada en esta dimensión como ocurre cuando se pretende ilustrar a las masas alienadas, dar vOz a los sin vOz, liderar las luchas sociales, revelar la verdad oculta por el Poder o erigirse en conciencia del

12 Para una reflexión sobre el vínculo entre "poesía” y “comunicación”, remito a Borra (2017a). 
mundo- constituye un error intelectual y político de primer orden ${ }^{13}$. No sin razón, habría que insistir que, como miembros de grupos específicos, de una clase social, de una formación histórica concreta, nuestra labor política más consecuente sería, en primer término, encarnar la transformación que impulsamos, eludiendo el discurso del amo que prescribe desde una presunta universalidad lo que debemos hacer para salvarnos. Si cuestionamos una misión mesiánica de la poesía, entonces, la consecuencia que de ello se deriva es que necesitamos distinguir, en términos políticos, el deseo legítimo del sujeto poético de participar en la producción de un cambio subjetivo e institucional de la (auto)atribución de unos privilegios enunciativos o una posición centralizada de poder (que no nos corresponde por derecho) en función de ese deseo. Por lo dicho, no cabe esperar nada diferente de los poetas que del resto de la ciudadanía: un compromiso con un cambio que depende, en cualquier caso, de la construcción de una voluntad colectiva y no solamente de nuestras añoranzas individuales. Si en el primer caso se concibe al poeta -en la línea de la mitología romántica- como sujeto privilegiado, portador de un saber emancipador que cabría transmitir mediante un proceso unidireccional de adoctrinamiento, en el segundo caso se trata de un sujeto simétrico, productor de unos sentidos que cabe confrontar con otros interlocutores, mediante un proceso multidireccional de diálogo. 14

4) En cuanto a la figura del lector $u$ oyente es relativamente sencillo derivar implicaciones de cada postura. Mientras que la perspectiva instrumentalista lo concibe como un simple receptor necesitado de ilustración para lograr una finalidad política transformadora, desde una perspectiva constructivista el lector/oyente es concebido como un interlocutor, necesitado de diálogo. Si la primera posición infla al poeta en detrimento del destinatario, en la segunda posición la devaluación del sujeto poético conduce a un reconocimiento de la centralidad del destinatario como (co)productor de sentido. En tanto un sujeto poético mesiánico no necesita semejantes sino seguidores, un sujeto poético que reconoce sus limitaciones no necesita seguidores sino semejantes con los que poder construir e intercambiar sentidos con respecto al mundo histórico-social en

13 Aunque semejante mesianismo tiene una génesis religiosa, puede rastrearse en la modernidad en su vertiente política, especialmente en cierto iluminismo de izquierdas que se atribuye a sí mismo una posición de saber y poder privilegiada en tanto representación directa de lo Universal. ¿ No es ese mesianismo uno de los riesgos fundamentales de las prácticas poéticas críticas -y tanto más si apostamos por un cambio social radical-, complementario al riesgo de sustraer al propio poeta de los procesos sociales que cuestionamos? Aunque no puedo explayarme en este contexto, a mi entender, desde el momento en que se admite teóricamente la incompletitud y precariedad como constitutivas del sujeto, necesariamente se expulsa la posibilidad de un Sujeto no barrado que podría asumir plenamente la representación de lo Universal. Tal como argumentan desde posiciones diferenciadas (y, eventualmente, controversiales) Butler, Zîzêk y Laclau, el reconocimiento de la condición limitada de todo agente histórico supone, en este sentido, el pasaje de un universalismo abstracto a un universalismo concreto, lo que implica desplazarse del mesianismo como política redentora hacia una política articulatoria y transaccional necesariamente inestable que llamamos "hegemonía» “(...) en tanto define el terreno mismo en que una relación política se constituye verdaderamente" (Laclau, en VVAA, 2004: 49).

14 Partir de esta simetría no significa en lo más mínimo que ese proceso comunicacional deba interpretarse desde una concepción comunicacional funcionalista ni, mucho menos, que dicho proceso deba pensarse desde el tamiz normalizador de propuestas estéticas dirigidas a un presunto "lector normal". Por el contrario, se trata de problematizar el lugar que habitualmente se le asigna a la figura del lector (Borra, 2018). 
el que ambos participan. Cuanto más se magnifique el rol del enunciador más se restringirá la actividad interpretativa del destinatario. Dicho lo cual, propiciar el descentramiento del sujeto no puede significar nada distinto a desmontar el mito de omnipotencia que está presupuesto en toda tentativa redentora y a cuestionar una cierta ansiedad hiperactiva que el sentido de la urgencia produce. Paradójicamente, mientras la primera posición inferioriza al destinatario en nombre de un Gran Otro mediante el que se autoriza (sea el Pueblo, la Comunidad o la Revolución), planteando una relación asimétrica y paternalista, la segunda posición admite su condición parcial y precaria, reconociendo al destinatario como sujeto comunicativo, en relaciones de igualdad, que participa en la construcción de una politica de lo común. ${ }^{15}$

$-\mathrm{IV}-$

Sostener la existencia de un vínculo indisociable entre práctica y lenguaje, como una de sus formas concretas, dista de la hipótesis solipcista de que no bay nada fuera. Lo que en cambio sostiene es que la simbolización de la "realidad" requiere necesariamente el uso de un lenguaje determinado que arrastra consigo las diversas cargas semánticas de su historia. Revisar esas cargas, producto de las luchas sociales, forma parte de la tarea crítica de quien escribe.

Puesto que cualquier práctica discursiva se mueve en diferentes planos significantes (lingüísticos, gestuales, corporales, rituales), el mentado pasaje a la acción está mal planteado. Como animales simbólicos, los sujetos humanos moramos en el lenguaje: es una de las condiciones o especificidades que nos distinguen o diferencian de otras especies. No podemos salir de esa condición como no sea negándonos a nosotros mismos ${ }^{16}$. Dicho de forma elíptica: un pasaje a la acción que supuestamente dejara atrás el lenguaje no sería un momento revolucionario sino un momento de locura: la imposibilidad misma de formarse un específico "sentido de realidad", base de toda práctica política, cualquiera fuera su signo. De este modo, ante la interpelación que se le hace a la poesía en nombre del activismo político, cabría responder con Auster: puede que el discurso de la urgencia no conduzca más que a la creación de artefactos explosivos, más o menos inofensivos. Es dudoso, sin embargo, que consiga algún cambio como no sea horadando el orden simbólico hegemónico que estructura, no sin resistencias, las prácticas sociales cotidianas. No es de extrañar, por tanto, que la mejor literatura se rebele contra lo urgente y se constituya como necesaria labor crítica. Si la ilusión de inmediatez descansa en una visión instrumentalista del

15 Como he sugerido en otras ocasiones, la construcción de una política de lo común tiene como uno de sus principales obstáculos la persistencia de grupos poéticos que operan como auténticos "clanes", planteando lógicas dicotómicas que se limitan a desconocer en términos estratégicos aquellos autores que desbordan (y cuestionan) sus fronteras. He ahondado en dicha reflexión sociológica en torno al campo poético español en (2013 y 2017b).

16 Afirmar semejante especificidad humana no implica, por lo demás, jerarquizar las diferencias entre especies para privilegiar en términos ontológicos a la especie humana, como presunto peldaño superior en la escala evolutiva. Por el contrario, una antropología materialista, a la vez que reconoce las especificidades materiales del sujeto humano (comenzando por el lenguaje articulado), reenvía al mundo animal al que pertenece. De forma inversa, tampoco supone negar el uso de sistemas sígnicos por parte de otras especies -tal como plantea la zoosemiótica- sino que insiste en la condición distintiva y constitutivamente humana del lenguaje (verbal), sin que ello implique una forma de antropocentrismo o, lo que sería más grave, una justificación al maltrato de las otras especies en nombre de una diferencia jerarquizada. 
lenguaje, una visión constructivista no reclama a la literatura nada distinto que la elaboración de obras de lenguaje críticamente elucidadas, tanto en términos formales como semánticos, capaces de entrar en diálogo con diversos interlocutores (lo que se conoce como "pragmática comunicacional"). Puesto que nuestra conciencia es, estructuralmente, incompleta y precaria, se trata de pensar lo poético como un espacio abierto de intercambio simbólico donde los otros, más que apéndices de mi intencionalidad comunicativa, proceden como sujetos comunicativos que co-producen sentidos diversos en torno al mundo y a nosotros mismos.

Cuestionar radicalmente la sociedad del presente en la que participamos, por lo dicho, es una tarea distinta a la creación de un nuevo "poder pastoral". No tenemos por qué confundir una práctica transformadora con la conversión de lo político en una suerte de religión que nos redimiría de la historia sustrayéndonos de su influjo. Quien descree de estos bálsamos y plantea lo político como "práctica del disenso" (Mouffe, 2007), ${ }^{17}$ se asume como sujeto político limitado; un sujeto que no se reduce a atestiguar el dolor o la violencia sistémica en la que nos movemos sino que también arriesga sus propias tentativas. Desde esa conciencia de los límites se hace pensable, precisamente, una constelación de poéticas que, en sus mejores variantes, constituyen un espacio explosivo que nos desplaza más allá del presente. O, como dice Negroni (2012: 16) a propósito de los argonautas, a inventar " $[\mathrm{u}] \mathrm{n}$ mundo, en suma, para vivir fuera del mundo", no como forma de escapismo sino como modo de resistir y anticipar un mundo otro en la propia existencia social o, dicho en otros términos, como táctica crítica para desplazarnos de toda fantasía de omnipotencia sin renunciar por ello a lo utópico. ${ }^{18}$

Más allá de la épica del sujeto, lo que en todo caso cabe seguir interrogando son nuestros compromisos en común y, en el caso de la literatura, este modesto oficio de escribir con la esperanza de contribuir a un cambio que nos implica de forma colectiva. Al fin de cuentas, a diferencia de Aaron que escribe todavía para ganarse la vida, puede que en este contexto histórico regresivo sigamos escribiendo para que nuestras vidas no se reduzcan a la mera supervivencia.

\footnotetext{
17 Si la visión común es antipolítica, en cuanto niega la dimensión antagónica constitutiva de lo político, una concepción agonista de lo político presupone el disenso como condición insoslayable. Así, a diferencia de autores como Hannah Arendt o Jürgen Habermas, que interpretan lo político como espacio deliberativo y consensual, la perspectiva de Mouffe enfatiza lo político como espacio de poder, conflicto y antagonismo (Mouffe, $2007: 16$ y ss.). Si bien no cabe una mera contraposición entre estas perspectivas teóricas, las diferencias conceptuales entre el "consenso racional" habermasiano y el "consenso" producto de específicas articulaciones hegemónicas son, a mi entender, irreductibles, tal como es planteado en Laclau y Mouffe (2010), en cuanto están necesariamente atravesadas por específicas relaciones de poder. Mientras que la teoría de la "acción comunicativa" de Habermas supone como ideal un "diálogo sin coacciones", la teoría de la hegemonía supone una negociación discursiva en la que la dimensión del poder es irreductible y, por tanto, insuprimible (Laclau, 2000).

18 Introducir cierto desorden, en ese punto, forma parte de una necesidad vital, favoreciendo “(...) la construcción de un lenguaje insumiso contra la clausura y las formas rígidas que impone siempre el realismo del poder" (Negroni, 2012: 8).
} 


\section{BIBLIOGRAFÍA}

ADORNO, Theodor (2008). Dialéctica negativa- La jerga de la autenticidad. Obra completa 4. Madrid: Akal.

AdORnO, Theodor(1983). Teoría estética. Barcelona: Orbis.

AusTER, Paul (1993). El Leviatán. Barcelona: Anagrama.

Austin, John (1982). ¿Cómo hacer cosas con palabras? Barcelona: Paidós.

BAjTIN, Mijail (1982). Estética de la creación verbal. México DF: Siglo XXI.

Borra, Arturo (2013). "Para una crítica por venir. Observaciones en torno al campo poético español", en "Rebelión", versión electrónica en http://www.rebelion.org/noticia.php? id $=168313$.

BOrRA, Arturo (2017a). Poesía como exilio. En los límites de la comunicación. Zaragoza: Unizad.

BORRA, Arturo (2017b). "El sujeto omitido: poéticas en diáspora en España”, en Revista Academia Canaria de la Lengua.

BORRA, Arturo. “La invención del lector”, en Revista Caja Nocturna 2 (2018): 24-31.

FALCÓN, Enrique (ed., 2007): Once poéticas críticas. Madrid: Centro de Documentación crítica.

FALCÓN, Enrique (2010): Las prácticas literarias del conflicto. Madrid: La oveja roja.

García Teresa, Alberto (2015). Disidentes. Madrid: La oveja roja.

HABERMAS, Jürgen (1987-1988). Teoría de la acción comunicativa. Madrid: Taurus.

HABERMAS, Jürgen(2011). Escritos filosóficos 1. Fundamentos de la sociología según la teoría del lenguaje.

IsER,Wolfgan (1987). El acto de leer. Madrid: Taurus.

Jameson, Fredric (1980). La cárcel del lenguaje. Perspectiva crítica del estructuralismo y del formalismo ruso. Barcelona: Ariel.

LACLAU, Ernesto (2000). Nuevas reflexiones sobre la revolución en nuestro tiempo. Buenos Aires: Nueva Visión.

LaClau, Ernesto y MoufFe, Chantal (2010). Hegemonía y estrategia socialista. Buenos Aires: Fondo de Cultura Económica.

MÉndez Rubio, Antonio (2008). La destrucción de la forma (y otros escritos sobre poesía y conflicto). Madrid: Biblioteca Nueva.

MoufFe, Chantal (2007). En torno a lo político. Buenos Aires: FCE.

Negroni, María (2012). Pequeño mundo ilustrado. Buenos Aires: Caja Negra.

Orozco, Olga (1998). Eclipses y fulgores. Barcelona: Lumen.

RiechmanN, Jorge (2007): "Poesía que no cede a la hipnosis", en FAlCón, Enrique (ed.): Once poéticas críticas. Madrid: Centro de Documentación crítica. 
SEARLE, John (1994): Actos de habla. Buenos Aires: Agostini.

VVAA (2004): Contingencia, hegemonía, universalidad. Diálogos contemporáneos en la irquierda. Buenos Aires: Fondo de Cultura Económica.

VERÓN, Eliseo (1988): La semiosis social. Barcelona: Gedisa.

VOLOSHINOV, Valentín (1993): El marxismo y la filosofía del lenguaje. Madrid: Alianza.

WiTTGENSTEIN, Ludwig (1988): Investigaciones filosóficas. Barcelona: Crítica. 